\title{
Determination of the Total Phenolic and Flavonoid in Various Extracts of Adiantum capillus veneris Linn, as well as their Radical Scavenging Activity
}

\section{Naema M El Aali*, Salah N Bugrein, Mohammed F El-Fellah, Maraia F Elmhdwi and Yusra F Layas}

Chemistry Department, Faculty of Science, Benghazi University, Libya

*Corresponding Author: Naema M El Aali, Chemistry Department, Faculty of Science, Benghazi University, Libya.

Received: November 28, 2017; Published: December 06, 2017

DOI: 10.31080/ASMI.2018.01.0002

\section{Abstract}

Adiantum capillus veneris linn is a member of Adiantaceae family which has been used as a folk medicine in management of hyperglycemia. Although there are some reports showing that the aqueous extract of the plant is effective as hypoglycemic agent but there were no scientific reports for its effectiveness.

The powdered dried leaves of A. capillus veneris L. was extracted continuously by Soxhelt extractor, five extracts (water, methanol, chloroform, ethyl acetate and acetone) were obtained and evaporated to dryness by rotatory evaporator. The extracts were investigated for antioxidant activity, reducing power and the presence of phenolic and flavonoid compounds.

The antioxidant activity of $A$. capillus veneris $\mathrm{L}$. was confirmed for all extracts with the highest activity for the water extract $\mathrm{IC}_{50}$ $=2.7$, this assay was also supported with reducing power assay, in which both methanolic extract and water extract exhibited the highest reducing power assay, while the ethyl acetate extract shows the highest total flavonoids content. The highest total phenolic content value was recorded for methanolic extract.

Keywords: Adiantum capillus veneris Linn; Antioxidant; Reducing Power; Flavonoids; Phenolic

\section{Introduction}

The knowledge about use of medicinal plants has been accrued through centuries time and such plants are still valued even today, although synthetics, antibiotics etc. have attained greater prominence in modern medicine. It is, however, a fact that these synthetics and antibiotics although they often show miraculous and often instantaneous results, prove harmful in the long run and this is why many synthetics and antibiotics have now gone out of use or suggested to be used under medicinal supervision. In the case of most medicine plants, however, no such cumulative derogatory effect has been recorded and many of medicines obtained from plants are widely used [1].

The World Health Organization (WHO) defines traditional medicine as: "the health practices, approaches, knowledge and beliefs incorporating plant, animal and mineral based medicines, spiritual therapies, manual techniques and exercises, applied singularly or in combination to treat, diagnose and prevent illnesses or maintain well-being [2].

A. capillus veneris $\mathrm{L}$. has potential importance in medicinal and nutritive purpose. It is used for chest complaints, cough, expectorant and for increasing lactation, colds, kidney function improvement, anti-parasitic and dandruff. Also it is used for depurative, emetic, emollient, febrifuge, galactagogue, Alopecia and tonic [3]. Furthermore this plant reported to be useful as de-toxicant in alcoholism and to expel worms from the body [4], and to has positive modulation of oxidation-linked diseases such as diabetes [5].

Free radicals chemical reactions and several redox reactions of various compounds may cause protein oxidation, DNA damage and lipid per-oxidation in living cells [6]. Therefore, oxidation have been claimed to play an important role in human health im- plicated in several diseases, including cancer, hypertension, heart attack, aging and diabetes. However, living organisms have developed antioxidant systems to counteract reactive species and to reduce their damage. These complex antioxidant systems include enzymes, such as superoxide dismutase (SOD and catalase (CAT). In addition to enzymatic system, an array of small molecules has been discovered in the past few decades such as glutathione (GSH) macromolecules, ascorbic acid, $\alpha$-tocopherol, carotenoids, polyphenols, uric acid and bilirubin. Many researches showed that oxidative damage occurs when this system is overwhelmed [5,7].

In a biological system, an antioxidant can be defined as "any substance that when present at low concentrations compared to that of an oxidizable substrate would significantly delay or prevent oxidation of that substrate" [8].

Antioxidants could protect the human body against free radicals that may cause pathological conditions, such as anaemia, arthritis, inflammation, neurodegeneration, aging process and perhaps dementias [5].

Although the folk medicine has been used from long time by populations in treatment of different disease, there is a lack of data regarding the effectiveness of different plants. Therefore, this study was deemed worthwhile to connect folk medicine with scientific prove by antioxidant activity testing to A. capillus veneris $\mathrm{L}$.

\section{Exclusion criteria}

\section{Plant Collection and Identification}

Samples of A. capillus veneris $\mathrm{L}$. were collected from the valleys of Derna - Libya during the winter of 2011 - 2012, the botanical identification of $A$. capillus veneris $\mathrm{L}$. was determined with the aid of the description given by the Libyan Flora and was eventually confirmed by comparison with authentic samples obtained from 
Determination of the Total Phenolic and Flavonoid in Various Extracts of Adiantum capillus veneris Linn, as well as their Radical Scavenging Activity

herbarium of the Department of Botany University of Benghazi. The plant were allowed to dry at room temperature and the leaves were then ground into powder state using a commercial blender, and finally used for the preparation of different extracts.

\section{Plant Extraction}

Aqueous Extract: Powdered plant (25g) was extracted with 250 $\mathrm{ml}$ of distilled water by Soxhelt extractor (size 29 - 24) for $24 \mathrm{hrs}$. Then evaporated to dryness at $70-80^{\circ} \mathrm{C}$ by Rotatory evaporator (RE2000).

Methanol, Chloroform, Ethyl acetate and Acetone Extracts: Powdered plants $(40 \mathrm{~g})$ was divided into four parts $(10 \mathrm{~g}$ for each part), the first part were extracted by methanol for $12 \mathrm{hrs}$, the second, third and fourth parts was extracted with chloroform, ethyl acetate and acetone respectively for $8 \mathrm{hrs}$. The extracts were evaporated to dryness by rotatory evaporator at $40^{\circ} \mathrm{C}$ for the methanolic extract and $50^{\circ} \mathrm{C}, 60^{\circ} \mathrm{C}$ and $40^{\circ} \mathrm{C}$ for chloroform, ethyl acetate and acetone extracts respectively.

\section{Chemicals}

1,1-Diphenylpicrylhydrazyl (DPPH) was obtained from Sigma Chemicals. Chemicals such as Chloroform, methanol, ethyl acetate, acetone, copper sulfate, ascorbic acid and monobasic dihydrogen phosphate were obtained from Merck company, ferric chloride, sodium nitrite, acetic anhydride, aluminum chloride, potassium iodide, sodium Chloride, methanol and sodium carbonate were obtained from Farmitalia Carlo Erba. Dibasic monohydrogen phosphate, trichloro acetic acid, Ninhydrin reagent and sodium hydroxide were obtained from Redeal De Haennagtca. Potassium ferricyanide was obtained from NICE company. Alloxan monohydrate, iodine, potassium bismuth iodide, magnesium turning and acetone were obtained from BHD.

Sulfuric acid was obtained from Fixanal, ammonia was obtained from PRS Panreac, dichloromethane was obtained from Ferak Berlin, hydrochloric acid was obtained from APS Finechem, lead acetate was obtained from T-Baker lab chemicals.

DPPH free radical scavenging assay (RSA)

Solution of DPPH $(0.2 \mathrm{mM})$ in methanol was prepared by dissolving $0.008 \mathrm{mg}$ of DPPH in $100 \mathrm{ml}$ of methanol. The DPPH radical scavenging activity of $A$. capillus veneris $\mathrm{L}$. were determined according to the method described by Tang., et al (2002). Five different extracts of methanol, ionized water, ethyl acetate, chloroform and acetone were dissolved in methanol and different concentration of $(100,200,300,400$ and $500 \mathrm{mg} / \mathrm{L})$ were prepared and $400 \mu \mathrm{l}$ of the different concentrations of $A$. capillus-veneris $\mathrm{L}$ extracts were added to $2 \mathrm{ml} \mathrm{DPPH} \mathrm{(0.02} \mathrm{mM).} \mathrm{The} \mathrm{Mixture} \mathrm{was} \mathrm{Kept} \mathrm{in} \mathrm{dark} \mathrm{for} 30 \mathrm{~min}$ utes at room temperature. The absorbance was read at $514.5 \mathrm{~nm}$ using spectrophotometer CE 7400, with solvent methanol as blank.
The scavenging activity (\%) was calculated according to the equation as follows:

$\% \mathrm{RSA}=[(\mathrm{ADPPH}-\mathrm{AS}) / \mathrm{ADPPH}] \cdot 100$

where AS is the absorbance of the solution when the sample extract has been added at a particular level, and ADPPH is the absorbance of the DPPH solution [9].

\section{Total Phenolic content}

The total phenolic content was determined using colorimetric method and expressed as Pyrogallol equivalents according to the method proposed by Singleton., et al. in 1999. To 100 of 100, 200, 300,400 , and $500 \mathrm{mg} / \mathrm{L}$ of the different extracts $2 \mathrm{ml}$ of de-ionized water were added and mixed with $600 \mu \mathrm{l}$ of Folin-Cicalteau reagent, the tube was allowed to stand at room temperature for 5 minutes, and $2 \mathrm{ml}$ of $20 \%$ sodium carbonate were add and kept at boiling water bath for 1 minute, after cooling the blue color formed measured at $765 \mathrm{~nm}$ by Aquarins (CE700) spectrophotometer Cecil instruments [10].

\section{Reducing power assay}

This assay was determined according to the method of Oyaizu (1986). $2.5 \mathrm{ml}$ of 100, 200, 300, 400, and $500 \mathrm{mg} / \mathrm{L}$ A. cappillus veneris $\mathrm{L}$. extracts were mixed with $2.5 \mathrm{ml}$ of $(0.2 \mathrm{M}, \mathrm{pH} 6.6)$ sodium phosphate buffer and $2.5 \mathrm{ml}$ of $1 \%$ potassium ferricyanide $\left[\mathrm{K}_{3} \mathrm{Fe}(\mathrm{CN})_{6}\right]$, then the mixture was incubated at $50^{\circ} \mathrm{C}$ for $20 \mathrm{~min}-$ utes. $2.5 \mathrm{ml}$ of $10 \%$ trichloroacetic acid $(\mathrm{w} / \mathrm{v})$ were added, the mixture was centrifuged at $1000 \mathrm{rpm}$ for 8 minutes (Centorion K240R-2003 refrigerated centrifuge). The upper layer ( $5 \mathrm{ml}$ ) was mixed with $5 \mathrm{ml}$ of de-ionised water and $1 \mathrm{ml}$ of $0.1 \%$ of ferric chloride, and the absorbance was measured spectrophotometrically at $700 \mathrm{~nm}$. Ascorbic acid was used to produce the calibration curve [11].

\section{Total Flavonoid Content By Spectrophotometer}

The determination of total flavonoids was performed according to the colorimetric assay. $4 \mathrm{ml}$ of de-ionized water was added to $1 \mathrm{ml}$ of $100,200,300,400$, and $500 \mathrm{mg} / \mathrm{L}$ of the different extracts of the sample. $0.3 \mathrm{ml}$ of $5 \%$ sodium nitrite solution were added followed by $0.3 \mathrm{ml}$ of $10 \%$ aluminum chloride solution. The mixture were incubated at ambient temperature for 5 minutes, and then $2 \mathrm{ml}$ of $1 \mathrm{M}$ sodium hydroxide were added to the mixture. Immediately, the volume of reaction mixture was made to $10 \mathrm{ml}$ with de-ionized water. The absorbance of the pink color developed was determined at $510 \mathrm{~nm}$. A calibration curve was prepared with quercetin and the results were expressed as mg quercetin equivalents per gram dry weight of sample [12]. 


\section{Result and Discussion}

Antioxidant activity assay

1,1'-diphenyl-2-picrylhydrazyl (DPPH) reactivity is one popular method for screening the free radical-scavenging ability of compounds or the antioxidant activity of plant extracts, and has been used extensively as a free radical to evaluate reducing substances. The use of DPPH provides an easy and rapid way to evaluate antioxidants. The effect of antioxidant on DPPH radical scavenging was thought to be due to their hydrogen donating ability. DPPH is a sta- ble free radical and accepts an electron or hydrogen radical to become a stable diamagnetic molecule DPP-Hydrazine [13]. Tables 1 and 2 show the percentage of inhibition values (\%Inh) for DPPH radical-scavenging of Methanol, Water, Chloroform, Ethyl acetate and Acetone extracts of $A$. capillus veneris $\mathrm{L}$. The data were compared to Ascorbic acid which is a synthetic antioxidant standard. Figure 1 shows percentage of inhibition of DPPH radical scavenging of different extracts and ascorbic acid. Standard division (SSD) had been measured.

\begin{tabular}{|l|c|c|c|c|c|c|}
\hline \multirow{2}{*}{$\begin{array}{c}\text { Concentration } \\
\text { “ } \boldsymbol{\mu g} / \mathbf{m l} \text { ” }\end{array}$} & \multicolumn{2}{|c|}{ Ascorbic acid } & \multicolumn{2}{c|}{ Methanol } & \multicolumn{2}{c|}{ Water } \\
\cline { 2 - 7 } & SSD & \% Inh & SSD & \% Inh & SSD & \% Inh \\
\hline 100 & $1.570 \pm 0.0212$ & $44.00 \%$ & $1.558 \pm 0.02$ & $28.53 \%$ & $1.400 \pm 0.012$ & $35.77 \%$ \\
\hline 200 & $1.281 \pm 0.00308$ & $54.00 \%$ & $1.392 \pm 0.013$ & $36.14 \%$ & $1.058 \pm 0.008$ & $51.46 \%$ \\
\hline 300 & $0.907 \pm 0.0040$ & $67.00 \%$ & $1.010 \pm 0.007$ & $53.67 \%$ & $1.014 \pm 0.019$ & $53.48 \%$ \\
\hline 400 & $0.555 \pm 0.00406$ & $80.00 \%$ & $0.792 \pm 0.004$ & $63.66 \%$ & $0.958 \pm 0.007$ & $56.05 \%$ \\
\hline 500 & $0.0870 \pm 0.03$ & $96.00 \%$ & $0.686 \pm 0.015$ & $68.53 \%$ & $0.857 \pm 0.005$ & $60.68 \%$ \\
\hline
\end{tabular}

Table 1: Antioxidant activity assay for Ascorbic acid, Methanol and Water extracts of A. capillus veneris L. leaves

\begin{tabular}{|l|c|c|c|c|c|c|}
\hline \multirow{2}{*}{$\begin{array}{c}\text { Concentration } \\
\boldsymbol{\mu} \boldsymbol{\mu g} / \mathbf{m l} \text { " }\end{array}$} & \multicolumn{2}{|c|}{ Chloroform } & \multicolumn{2}{c|}{ Ethyl acetate } & \multicolumn{2}{c|}{ Acetone } \\
\cline { 2 - 7 } & SSD & \% Inh & SSD & \% Inh & SSD & \% Inh \\
\hline 100 & $1.614 \pm 0.012$ & $25.96 \%$ & $1.676 \pm 0.006$ & $23.11 \%$ & $1.905 \pm 0.03$ & $12.61 \%$ \\
\hline 200 & $1.535 \pm 0.014$ & $29.58 \%$ & $1.587 \pm 0.007$ & $27.20 \%$ & $1.823 \pm 0.05$ & $16.38 \%$ \\
\hline 300 & $1.454 \pm 0.007$ & $33.30 \%$ & $1.474 \pm 0.012$ & $32.38 \%$ & $1.792 \pm 0.05$ & $17.80 \%$ \\
\hline 400 & $1.349 \pm 0.014$ & $38.11 \%$ & $1.440 \pm 0.007$ & $33.94 \%$ & $1.758 \pm 0.03$ & $19.36 \%$ \\
\hline 500 & $1.158 \pm 0.008$ & $46.88 \%$ & $1.324 \pm 0.007$ & $39.26 \%$ & $1.745 \pm 0.03$ & $19.95 \%$ \\
\hline
\end{tabular}

Table 2: Antioxidant activity assay for Chloroform, Ethyl acetate and Acetone extracts of A. capillus veneris L. leaves

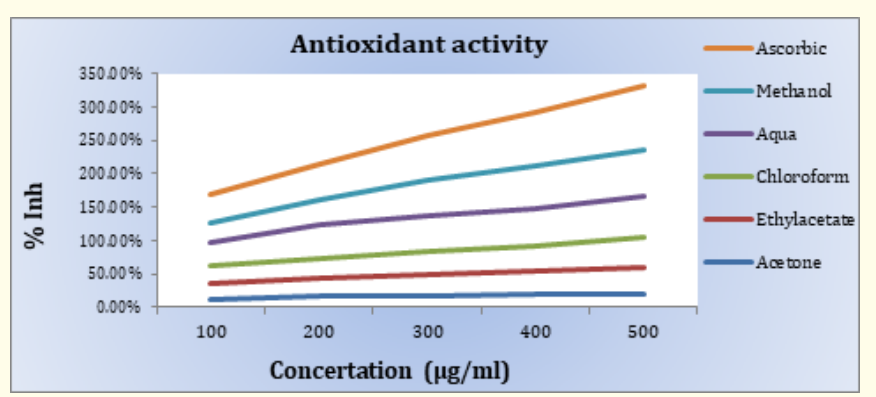

Figure 1: DPPH radical scavenging activity of different extracts of $A$. capillus veneris $\mathrm{L}$. in different solvents. Ascorbic acid used as standard.

Concentration of the sample necessary to decrease initial concentration of DPPH• by $50 \%\left(\mathrm{IC}_{50)}\right.$ under the experimental condition was determined. Therefore, the lower value of $\mathrm{IC}_{50}$ indicates a higher antioxidant activity [14]. Table 3 shows the $\mathrm{IC}_{50} \%$ value for the different extracts used in the study.

\begin{tabular}{|c|c|}
\hline Solvent & IC $_{\mathbf{5 0}}$ \% \\
\hline Ascorbic acid & 1.6 \\
\hline Water & 2.7 \\
\hline Methanol & 2.99 \\
\hline Chloroform & 6.02 \\
\hline Ethyl acetate & 7.79 \\
\hline Acetone & 21.51 \\
\hline
\end{tabular}

Table 3: The $\mathrm{IC}_{50}$ values for $A$. capillus veneris $\mathrm{L}$. leaves in various extracts.

According to the $\mathrm{IC}_{50} \%$ values the water extract showed particularly high antioxidant activity with $\mathrm{IC}_{50} \%$ of $2.7 \mu \mathrm{g} / \mathrm{ml}$ which is one time lower than the ascorbic acid with $\mathrm{IC}_{50} \%$ value of 1.6 followed by methanol, chloroform, ethyl acetate and acetone extracts.

\section{Total Phenolic cotenant}

Folin-Ciocalteu (F.C) reagent was used to determine total polyphenol in sample extracts. This reagent oxidises phenolates, re- 
Determination of the Total Phenolic and Flavonoid in Various Extracts of Adiantum capillus veneris Linn, as well as their Radical Scavenging Activity

sulting in the production of complex molybdenum-tungsten blue which can be detected spectrophotometrically at $765 \mathrm{~nm}$. F.C. reagent is employed routinely in studying phenolic antioxidants [3]. For the A. capillus veneris L. leaves extract, the phenolic content was found to be in the order of methanol > acetone $>$ ethyl acetate $>$ chloroform $>$ water as shown in table 4 . Methanol is a good solvent for $A$. capillus veneris $L$. as large amount of phenolics compounds are soluble in methanol when compared with other extracts.

\begin{tabular}{|l|c|c|c|c|c|c|}
\hline & \multicolumn{7}{|c|}{ Mean \pm Standard Deviation } \\
\hline Conc. $\boldsymbol{\mu} \boldsymbol{\mu g} / \mathbf{m l}$ " & Pyrogallol & Methanol & Acetone & Ethyl- acetate & Chloro-form & Water \\
\hline 100 & $0.292 \pm 0.005$ & $0.016 \pm 0.013$ & $0.006 \pm 0.005$ & $0.008 \pm 0.003$ & $0.005 \pm 0.001$ & $0.008 \pm 0.0020$ \\
\hline 200 & $0.494 \pm 0.003$ & $0.026 \pm 0.006$ & $0.012 \pm 0.003$ & $0.015 \pm 0.001$ & $0.012 \pm 0.004$ & $0.012 \pm 0.001$ \\
\hline 300 & $0.797 \pm 0.007$ & $0.032 \pm 0.006$ & $0.024 \pm 0.006$ & $0.028 \pm 0.001$ & $0.017 \pm 0.002$ & $0.020 \pm 0.005$ \\
\hline 400 & $0.857 \pm 0.002$ & $0.043 \pm 0.003$ & $0.030 \pm 0.005$ & $0.035 \pm 0.003$ & $0.023 \pm 0.004$ & $0.026 \pm 0.005$ \\
\hline 500 & $1.022 \pm 0.005$ & $0.054 \pm 0.006$ & $0.044 \pm 0.011$ & $0.043 \pm 0.019$ & $0.043 \pm 0.019$ & $0.028 \pm 0.001$ \\
\hline
\end{tabular}

Table 4: Total phenolic cotenant for pyrogallol, Methanol, Water, chloroform, ethyl acetate leaves extracts of $A$. capillus veneris L.

In general the amount of phenolic content when data were compared to Pyrogallol, which is a highly phenolic natural compound, was significantly low in all extract. Figure 2 shows the difference in total phenolic content for each extract and pyrogallol.

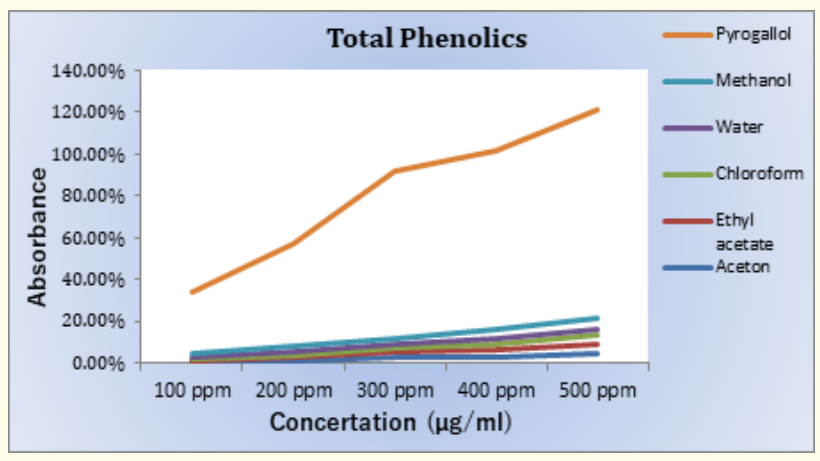

Figure 2: Total phenolic values of the different extracts from A. capillus veneris $\mathrm{L}$. in different solvents expressed in $\mu \mathrm{g} / \mathrm{ml}$. Pyrogallol is used as a standard.

\section{Total flavonoids content}

Total flavonoids can be determined in the sample extracts by reaction with sodium nitrite, followed by the development of colored flavonoid-aluminum complex using aluminum chloride which can be monitored spectrophotometrically at $510 \mathrm{~nm}$ [15]. The results as shown in table 5 showed that the ethyl acetate extract had the highest flavonoids content with a value of $0.263 \pm$ 0.077 (absorbance unit) followed by acetone, chloroform, methanol and finally the water extract which had the lowest flavonoids content with value of $0.082 \pm 0.004$. All data were compared to Quercetin, which is a flavonoid natural standard. Figure 3 shows the difference in total flavonoids content for each extract and quercetin.

\section{Reducing power}

The presence of reducers (i.e. antioxidants) causes the conversion of the $\mathrm{Fe}+3 /$ ferricyanide complex used in this method to the $\mathrm{Fe}+2$ /ferrous form. Therefore, by measuring the formation of Perl's Prussian blue at $700 \mathrm{~nm}$, we can monitor the Fe+2 concen-

\begin{tabular}{|l|c|c|c|c|c|c|}
\hline & \multicolumn{7}{|c|}{ Mean \pm Standard Deviation } \\
\hline Conc. “ $\boldsymbol{\mu g} / \mathbf{m l}$ " & Quercetin & Ethyl-acetate & Acetone & Chloro-form & Methanol & Water \\
\hline 100 & $0.236 \pm 0.003$ & $0.095 \pm 0.018$ & $0.119 \pm 0.025$ & $0.087 \pm 0.017$ & $0.139 \pm 0.005$ & $0.034 \pm 0.010$ \\
\hline 200 & $0.337 \pm 0.026$ & $0.134 \pm 0.020$ & $0.140 \pm 0.023$ & $0.116 \pm 0.030$ & $0.148 \pm 0.001$ & $0.042 \pm 0.006$ \\
\hline 300 & $0.442 \pm 0.087$ & $0.178 \pm 0.021$ & $0.167 \pm 0.016$ & $0.156 \pm 0.035$ & $0.159 \pm 0.001$ & $0.066 \pm 0.005$ \\
\hline 400 & $0.542 \pm 0.004$ & $0.205 \pm 0.040$ & $0.200 \pm 0.014$ & $0.171 \pm 0.039$ & $0.164 \pm 0.000$ & $0.076 \pm 0.004$ \\
\hline 500 & $0.588 \pm 0.006$ & $0.263 \pm 0.077$ & $0.230 \pm 0.004$ & $0.222 \pm 0.026$ & $0.178 \pm 0.005$ & $0.082 \pm 0.004$ \\
\hline
\end{tabular}

Table 5: Total flavonoids cotenant for Querceten, Methanol, Water, chloroform, ethyl acetate extracts for the leaves of A. capillus veneris L 
Determination of the Total Phenolic and Flavonoid in Various Extracts of Adiantum capillus veneris Linn, as well as their Radical Scavenging Activity

\begin{tabular}{|l|c|c|c|c|c|c|}
\hline & \multicolumn{7}{|c|}{ Mean \pm Standard Deviation } \\
\hline Conc. “ $\mu \mathrm{g} / \mathbf{m l}$ " & Ascorbic acid & Methanol & Water & Chloroform & Acetone & Ethyl acetate \\
\hline 100 & $0.293 \pm 0.012$ & $0.399 \pm 0.007$ & $0.370 \pm 0.044$ & $0.216 \pm 0.006$ & $0.229 \pm 0.024$ & $0.253 \pm 0.007$ \\
\hline 200 & $0.382 \pm 0.032$ & $0.433 \pm 0.012$ & $0.407 \pm 0.004$ & $0.224 \pm 0.002$ & $0.270 \pm 0.001$ & $0.255 \pm 0.004$ \\
\hline 300 & $0.445 \pm 0.008$ & $0.435 \pm 0.053$ & $0.426 \pm 0.004$ & $0.316 \pm 0.001$ & $0.284 \pm 0.004$ & $0.258 \pm 0.001$ \\
\hline 400 & $0.693 \pm 0.10$ & $0518 \pm 0.007$ & $0.470 \pm 0.055$ & $0.326 \pm 0.003$ & $0.328 \pm 0.024$ & $0.263 \pm 0.005$ \\
\hline 500 & $0.992 \pm 0.005$ & $0.535 \pm 0.028$ & $0.494 \pm 0.044$ & $0.350 \pm 0.002$ & $0.346 \pm 0.031$ & $0.310 \pm 0.000$ \\
\hline
\end{tabular}

Table 6: Reducing power for Ascorbic acid, Methanol, Water, chloroform, ethyl acetate and extracts for the leaves of $A$. capillus veneris L.

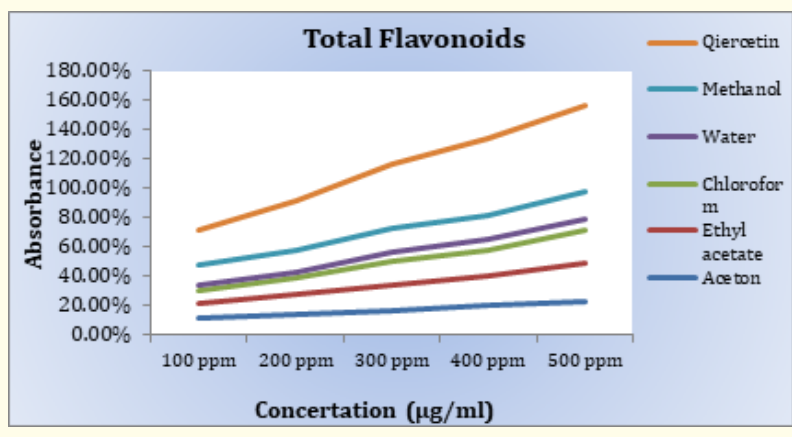

Figure 3: Total flavonoids values of the extract from A. capillus veneris $\mathrm{L}$. in different solvents expressed in $\mu \mathrm{g} / \mathrm{ml}$. quercetin was used as standard.

tration; a higher absorbance at $700 \mathrm{~nm}$ indicates a higher reducing power [15]. The results as shown in table 6 proved that the methanol extract had the highest reducing power content with a value of $0.535 \pm 0.028$ (absorbance unit) followed by water, chloroform, acetone and ethyl acetate, which had the lowest reducing power with value of $0.310 \pm 0.000$.

All data were compared to Ascorbic acid which has high reducing power ability. Figure 4 shows the difference in reducing power assay for each extract and ascorbic acid.

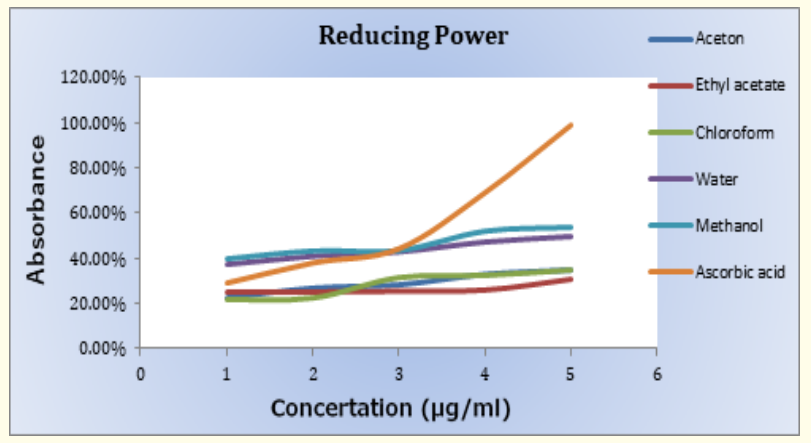

Figure 4: Reducing power assay of the extract from $A$. capillus veneris $\mathrm{L}$. in different solvents expressed in $\mu \mathrm{g} / \mathrm{ml}$. Ascorbic acid was used as standard.

All extract showed strong antioxidant activity with low significant difference, the highest reducing ability was for the methanolic extract with a value of $0.535 \pm 0.028$ (absorbance unit), which is 1.8 times lower than that for the standard ascorbic acid, while the water extract was 2 times lower than the standard.

\section{Conclusion}

The present study gave an insight into the effectiveness of different extracts of the plant $A$. capillus veneris $L$. as antioxidant in which the antioxidant activity of $A$. capillus veneris L. was confirmed for all extracts with the highest activity for the water extract $\mathrm{IC}_{50}=2.7$, and the lowest for the acetone extract $\mathrm{IC}_{50}=21.51$, this assay was also supported with reducing power assay, in which both methanolic extract and water extract exhibited the highest values $(0.535 \pm 0.028$ and $0.494 \pm 0.044)$ respectively at $500 \mu \mathrm{g} /$ $\mathrm{ml}$, while the ethyl acetate extract gave the lowest value $0.310 \pm$ 0.000 ) at $500 \mu \mathrm{g} / \mathrm{ml}$. The measurement of total flavonoids content was the highest value for the ethyl acetate extract $(0.263 \pm$ $0.077)$ at $500 \mu \mathrm{g} / \mathrm{ml}$, and the lowest value for water extract $(0.082$ \pm 0.004 ) at $500 \mu \mathrm{g} / \mathrm{ml}$. The highest total phenolic content value was recorded for methanolic extract $(0.054 \pm 0.006)$ at $500 \mu \mathrm{g} /$ $\mathrm{ml}$ and the lowest value for water extract $(0.028 \pm 0.001)$ at 500 $\mu \mathrm{g} / \mathrm{ml}$. All of these variations proved the antioxidant activity of all extracts of A. capillus veneris L. leaves.

\section{Bibliography}

1. Parihar and L Parihar. "Some pteridophytes of medicinal importance from Rajasthan". Natural Product Radiance 5.4 (2006): 297-301

2. J Eldredge. "The randomised controlled trial design: unrecognized opportunities for health sciences librarianship". Health Information and Libraries 20.1 (2003): 34-44.

3. NS Rajurkar and K Gaikwad. "Evaluation of phytochemicals, antioxidant activity and elemental content of Adiantum capillus veneris leaves". Journal of Chemical and Pharmaceutical Research 4.1 (2012): 365-374.

4. N Fatima., et al. "Study of some micronutrients in selected medicinal plants". Scientia Iranica 12.3 (2005): 269-273.

5. M Jiang., et al. "In vitro and in vivo studies of antioxidant activities of flavonoids from Adiantum capillus-veneris L". African Journal of Pharmacy and Pharmacology 15.8 (2011): 2079-2085.

6. Sharma AB., et al. "Reactive oxygen species, oxidative damage, and antioxidative defense Mechanism in plants under stressful conditions". Journal of Botany (2012). 
7. A Kunwar and KI Priyadarsini. "Free radicals, oxidative stress and importance of antioxidants in human health". Medical and Allied Sciences 1.2 (2011): 53-60.

8. Wanasundara and F Shahidi. "Antioxidants: Science, Technology, and Applications". Sixth edition. Bailey's Industrial Oil and Fat Products, ed. F. Shahidi. Volume 6 (2005): 489.

9. MS Blois. "Antioxidant determination by the use of a stable free radical". Nature 181 (1958): 1199-1200.

10. T Swan and W E Hillis. "The Phenolic Constituents of Prunus Domestica. I. The Quantitative Analysis of Phenolic Constituents". Journal of the Science of Food and Agriculture 10.1 (1959): 63-68.

11. M Oyaizu. "Studies on product of browning reaction prepared from glucose amine". Japanese Journal of Nutrition 44 (1986): 307-315.

12. J Zhishen., et al. "The determination of flavonoid contents in mulberry and their scavenging effects on superoxide radicals". Food Chemistry 64.4 (1999): 555-559.

13. G Morales., et al. "Antioxidant activity of $50 \%$ aqueous - ethanol extract from Acantholippia deserticola". Biological Research 41.2 (2008): 151-155.

14. S Kumar., et al. "Polyphenols, Vitamin-E estimation and in vitro antioxidant activity of Adiantum capillus-veneris". International Journal of Innovative Pharmaceutical Research 4.1 (2013): 258-262.

15. L Barros., et al. "Total phenols, ascorbic acid, b-carotene and lycopene in Portuguese wild edible mushrooms and their antioxidant activities". Food Chemistry 103.2 (2007): 413-419.

Volume 1 Issue1 January 2018

(C) All rights are reserved by Naema M El Aali., et al.

Citation: Naema M El Aali., et al. "Determination of the Total Phenolic and Flavonoid in Various Extracts of Adiantum capillus veneris Linn, as well as their Radical Scavenging Activity". Acta Scientific Microbiology 1.1 (2018): 04-09. 